\title{
Does ultrasound-guided infraclavicular block meet users' expectations?
}

\author{
José Aguirre, MD • Barbara Baulig, MD • \\ Alain Borgeat, MD, PhD
}

Received: 15 October 2009/Accepted: 9 November 2009/Published online: 7 January 2010

(C) Canadian Anesthesiologists' Society 2010

\section{To the Editor,}

We read with interest the recently published article by Brull et al. ${ }^{1}$ and have several concerns regarding the methods and conclusions of their work.

According to the literature cited in the introduction of their article, Brull et al. ${ }^{1}$ reported a $60-79 \%$ success rate for neurostimulator (NS)-guided infraclavicular block (ICB). However, the authors also cited a recent study by Sauter et $_{\text {al. }}{ }^{2}$ who reported a success rate of $85 \%$ using the same technique. Other experts report a success rate of $97 \%$ using NS. ${ }^{3}$ This selective choice of citations may lead to some confusion regarding the inference that ultrasound (US)-guided techniques are associated with a clinically relevant increase in block success rate. This hypothesis remains to be proven. Moreover, we are concerned with the authors' assertion that the highest success rate is associated with multiple cord stimulation, ${ }^{4,5}$ as a more recently published study showed that stimulation of the posterior cord achieves the most reliable response using NS. ${ }^{6}$

From the perspective of study design, there are several methodological limitations that may have negatively influenced the outcome of the NS group. ${ }^{1}$ Lecamwasam et $a l .{ }^{4}$ described that posterior cord stimulation is the preferred technique for NS-guided ICB with the highest success rate, followed by the medial cord and then the lateral cord. In Brull et al.'s study, stimulation of two cords was required in the NS group without considering the importance of the posterior cord, while the posterior cord was always blocked in the US group. Furthermore, the considerable range of stimulating current (from 0.3 to $0.5 \mathrm{~mA}$ ) may have led to a different block quality in the NS

J. Aguirre, MD $(\bowtie) \cdot$ B. Baulig, MD · A. Borgeat, MD, PhD Balgrist University Hospital, Zurich, Switzerland e-mail: jose.aguirre@balgrist.ch group. The variance in current amplitude may have precluded a valid comparison between these techniques. ${ }^{7,8}$

A further concern is that the studies cited by the authors for the dual motor response were performed using the coracoid approach rather than the sagittal approach. Using a US-guided dual motor response normally implies blocking the musculocutaneous nerve first, followed by a second nerve (with clear preference for the radial nerve). ${ }^{9}$ The definition of "block performance time" clearly favored the US group. Positioning the patient, starting the US machine, introducing patient data into the US device, sterile dressing of the probe, applying the gel, and pre-scanning time do not appear to have been considered. These time requirements may match the time required for patient positioning and identification of landmarks using a traditional approach. In the study reported by Sauter et al., ${ }^{2}$ no difference in performance time was observed when comparing the two techniques. A further concern is that the sample size calculation was performed using the lowest success rate reported in literature, suggesting that the study may have been underpowered.

Finally, the authors' interpretation of Sauter et al.'s study $^{2}$ may have been misleading. Contrary to Brull et al.'s report, ${ }^{1}$ Sauter et al. did not power their study to detect a five-minute difference in block onset time. Rather, their purpose was to detect a difference in "time until readiness for surgery." This is a clinically relevant endpoint (no difference between the groups) compared with block success as defined in the Brull study. These limitations compromise the conclusions that can be drawn from Brull et al.'s study, as they are not reported by experienced hands using NS. ${ }^{2,3,10}$ Future research in this area should be focused on major outcomes, including patient safety and development of new techniques using US-guided and NSguided blocks to further improve clinical outcomes. 
Disclosure of funding No funds were received in support of this work.

Conflicts of interest None declared.

\section{References}

1. Brull R, Lupu M, Perlas A, Chan VW, McCartney CJ. Compared with dual nerve stimulation, ultrasound guidance shortens the time for infraclavicular block performance. Can J Anesth 2009; 56: 812-8.

2. Sauter AR, Dodgson MS, Stubhaug A, Halstensen AM, Klaastad $O$. Electrical nerve stimulation or ultrasound guidance for lateral sagittal infraclavicular blocks: a randomized, controlled, observer-blinded, comparative study. Anesth Analg 2008; 106: 1910-5.

3. Borgeat A, Dullenkopf A, Ekatodramis G, Nagy L. Evaluation of the lateral modified approach for continuous interscalene block after shoulder surgery. Anesthesiology 2003; 99: 436-42.

4. Lecamwasam H, Mayfield J, Rosow L, Chang Y, Carter C, Rosow $C$. Stimulation of the posterior cord predicts successful infraclavicular block. Anesth Analg 2006; 102: 1564-8.

5. Bloc S, Garnier T, Komly B, et al. Single-stimulation, low-volume infraclavicular plexus block: influence of the evoked distal motor response on success rate. Reg Anesth Pain Med 2006; 31 : 433-7.

6. Rodriguez J, Taboada M, Oliveira J, Ulloa B, Barcena $M$, Alvarez $J$. Single stimulation of the posterior cord is superior to dual nerve stimulation in a coracoid block. Acta Anaesthesiol Scand 2009; doi:10.1111/j.1399-6576.2009.02110.x.

7. Neuburger $M$, Rotzinger $M$, Kaiser $H$. Electric nerve stimulation in relation to impulse strength. A quantitative study of the distance of the electrode point to the nerve (German). Anaesthesist 2001; 50: 181-6.

8. Eifert B, Hahnel J, Kustermann J. Axillary blockade of the brachial plexus. A prospective study of blockade success using electric nerve stimulation (German). Anaesthesist 1994; 43: 780-5.

9. Minville V, Fourcade $O$, Bourdet B, et al. The optimal motor response for infraclavicular brachial plexus block. Anesth Analg 2007; 104: 448-51.

10. Casati A, Danelli G, Baciarello $M$, et al. A prospective, randomized comparison between ultrasound and nerve stimulation guidance for multiple injection axillary brachial plexus block. Anesthesiology 2007; 106: 992-6.

\section{Reply}

Thank you for the opportunity to address the concerns of Aguirre et al. regarding our recently published study. ${ }^{1}$ Their letter raises a number of criticisms regarding the optimal neurostimulation technique (NS), our ultrasound technique (US), the calculation of block performance time, and our experience in using the NS-guided infraclavicular technique.

First, they are critical of our decision not to preferentially seek nerve stimulation of the posterior cord and offer the previously published trial by Lecamwasam et $a .^{2}$ as evidence. The purported superiority of posterior cord stimulation using NS guidance, either as the sole end-point for a single injection technique or as one end-point for a double injection technique, has never been shown in a prospective randomized double-blind study. In fact, a recent review ${ }^{3}$ published in the Journal concludes that the best combination of cords to stimulate has not been studied using a randomized design, and the best motor responses for a double-injection NS-guided technique for infraclavicular block warrant further investigation. The current amplitude and pulse width used in our study remains consistent with best practice, and there is no good quality study that demonstrates a difference in block success when $0.3 \mathrm{~mA}$ is compared with $0.5 \mathrm{~mA}$ at a pulse width of $100 \mu \mathrm{s}$. However, there are studies that demonstrate no difference in block success between commonly accepted low and high current amplitudes. ${ }^{4,5} \mathrm{We}$ feel that our use of the dual endpoint NS infraclavicular technique ${ }^{6}$ remains a very appropriate comparison with the US technique.

Contrary to the impression of Aguirre et al., the US technique that we used did not involve nerve stimulation. In addition, our block performance time in the US group included pre-scan time. Therefore, our data demonstrating that US significantly reduces performance time remains both clinically and statistically very significant. We agree that the NS method can often be performed very quickly, as demonstrated by our median and interquartile range data. However, this data also demonstrates that the procedure time was more than $17 \mathrm{~min}$ in $25 \%$ of patients in the NS group, and we could not identify appropriate responses in two patients within $20 \mathrm{~min}$. Similar supportive data has recently been published by Mariano et al. ${ }^{7}$ Since, much of the performance time in the NS group is spent seeking a nerve stimulation endpoint in the patient, we would argue that this is neither conducive to patient comfort nor safety. In addition, all blocks in this study were either performed or directly supervised by anesthesiologists who are experts with both the NS- and US-guided infraclavicular technique.

Aguirre et al. conclude that future research should be focused on major outcomes, including patient safety and development of new techniques using both US and NS to further improve clinical outcomes. We agree that larger studies are required to examine patient safety, and we congratulate Aguirre et al. on their acceptance that US has a significant place in the future practice of peripheral nerve blocks. However, several studies using combined US and NS techniques have demonstrated that this actually prolongs block performance time ${ }^{8-10}$ and that ultrasound alone consistently produces the fastest block time. ${ }^{10,11}$

We therefore maintain that our findings regarding the similarity of the overall success rates are valid when comparing ultrasound-guidance with dual motor endpoint stimulation for infraclavicular block. ${ }^{1}$ However, in experienced hands, ultrasound guidance does shorten performance time (5 min $v s 10.5 \mathrm{~min} ; P<0.001)$ and 
improves patient readiness for surgery $(85 \%$ vs $65 \%$; $P=0.04)$.

Conflicts of interest None declared.

\section{References}

1. Brull R, Lupu M, Perlas A, Chan VW, McCartney CJ. Compared with dual nerve stimulation, ultrasound guidance shortens the time for infraclavicular block performance. Can J Anesth 2009; 56: 812-8.

2. Lecamwasam H, Mayfield J, Rosow L, Chang Y, Carter C, Rosow $C$. Stimulation of the posterior cord predicts successful infraclavicular block. Anesth Analg 2006; 102: 1564-8.

3. De Tran QH, Clemente A, Doan J, Finlayson RJ. Brachial plexus blocks: a review of approaches and techniques. Can J Anesth 2007; 54: 662-74.

4. Franco CD, Domashevich V, Voronov G, Rafizad AB, Jelev TJ. The supraclavicular block with a nerve stimulator: to decrease or not to decrease, that is the question. Anesth Analg 2004; 98: 116771.

5. Riegler FX. Brachial plexus block with the nerve stimulator: motor response characteristics at three sites. Reg Anesth 1992; 17: 295-9.

6. Rodríguez J, Barcena M, Lagunilla J, Alvarez J. Increased success rate with infraclavicular brachial plexus block using a dual-injection technique. J Clin Anesth 2004; 16: 251-6.
7. Mariano ER, Loland VJ, Bellars RH, et al. Ultrasound guidance versus electrical stimulation for infraclavicular brachial plexus perineural catheter insertion. J Ultrasound Med 2009; 28: 1211-8.

8. Gurkan Y, Acar S, Solak M, Toker K. Comparison of nerve stimulation vs. ultrasound-guided lateral sagittal infraclavicular block. Acta Anaesthesiol Scand 2008; 52: 851-5.

9. Morros C, Perez-Cuenca MD, Sala-Blanch X, Cedo F. Contribution of ultrasound guidance to the performance of the axillary brachial plexus block with multiple nerve stimulation (Spanish). Rev Esp Anestesiol Reanim 2009; 56: 69-74.

10. Chan VW, Perlas A, McCartney CJ, Brull R, Xu D, Abbas $S$. Ultrasound guidance improves success rate of axillary brachial plexus block. Can J Anesth 2007; 54: 176-82.

11. Dingemans E, Williams $S R$, Arcand $G$, et al. Neurostimulation in ultrasound-guided infraclavicular block: a prospective randomized trial. Anesth Analg 2007; 104: 1275-80.

Colin J. L. McCartney, MBChB

Sunnybrook Health Sciences Centre, University of Toronto, Toronto, Canada

Richard Brull, MD

Anahi Perlas, MD

Vincent Chan, MD

Toronto Western Hospital, University of Toronto,

Toronto, Canada 